\title{
Strategies for reducing body fat mass: effects of liposuction and exercise on cardiovascular risk factors and adiposity
}

This article was published in the following Dove Press journal:

Diabetes, Metabolic Syndrome and Obesity:Targets and Therapy 19 April 2011

Number of times this article has been viewed

\author{
Fabiana Braga Benatti' \\ Fábio Santos Lira ${ }^{2}$ \\ Lila Missae Oyama ${ }^{2}$ \\ Cláudia Maria da Penha \\ Oller do Nascimento ${ }^{2}$ \\ Antonio Herbert Lancha \\ Junior ${ }^{\prime}$
}

'School of Physical Education and Sport, University of Sao Paulo, Sao Paulo, Brazil; ${ }^{2}$ Department of Physiology, Division of Nutrition Physiology, Federal University of Sao Paulo, Sao Paulo, Brazil
Correspondence: Fabiana Braga Benatti Av. Professor Mello Moraes, 65, CEP 05508-030, Sao Paulo, SP, Brazil

Tel +55 II 309। 3096

Fax +55 I| 3813 592।

Email fabenatti@usp.br
Abstract: Liposuction is the most popular aesthetic surgery performed in Brazil and worldwide. Evidence showing that adipose tissue is a metabolically active tissue has led to the suggestion that liposuction could be a viable method for improving metabolic profile through the immediate loss of adipose tissue. However, the immediate liposuction-induced increase in the proportion of visceral to subcutaneous adipose tissue could be detrimental to metabolism, because a high proportion of visceral to subcutaneous adipose tissue is associated with risk factors for cardiovascular disease. The results of studies investigating the effects of liposuction on the metabolic profile are inconsistent, however, with most studies reporting either no change or improvements in one or more cardiovascular risk factors. In addition, animal studies have demonstrated a compensatory growth of intact adipose tissue in response to lipectomy, although studies with humans have reported inconsistent results. Exercise training improves insulin sensitivity, inflammatory balance, lipid oxidation, and adipose tissue distribution; increases or preserves the fat-free mass; and increases total energy expenditure. Thus, liposuction and exercise appear to directly affect metabolism in similar ways, which suggests a possible interaction between these two strategies. To our knowledge, no studies have reported the associated effects of liposuction and exercise in humans. Nonetheless, one could suggest that exercise training associated with liposuction could attenuate or even block the possible compensatory fat deposition in intact depots or regrowth of the fat mass and exert an additive or even a synergistic effect to liposuction on improving insulin sensitivity and the inflammatory balance, resulting in an improvement of cardiovascular risk factors. Consequently, one could suggest that liposuction and exercise appear to be safe and effective strategies for either the treatment of metabolic disorders or aesthetic purposes.

Keywords: adipose tissue, inflammatory markers, exercise, insulin, metabolism

\section{Introduction}

The idea of the surgical removal of body fat mass from specific regions of the body is not recent. The first attempt was performed in France in 1921, when Charles Dujarrier removed the subcutaneous fat of the calves and knees of a female dancer using a uterine curette. The disastrous outcome was the amputation of the dancer's leg. During subsequent years, other physicists and scientists developed different techniques to remove subcutaneous body fat. However, all of these techniques resulted in undesirable hematomas and/or scars. ${ }^{1}$

The field of modern liposuction was initiated in 1974 by Arpad and Giuliano Fischer in Italy. It was only in 1987, however, that Jeffrey Klein innovated the field by developing the tumescent technique, which eliminated the high risk of excessive bleeding that is usually observed during liposuction surgeries, making it a much safer procedure. ${ }^{2}$ 
The development of the tumescent technique allowed the removal of greater amounts of fat in a much safer environment. This innovation, together with the knowledge that adipose tissue is a very metabolically active organ, ${ }^{3}$ led scientists to believe that liposuction could be a viable method for improving metabolic profile through the immediate loss of body fat mass, thus functioning as a possible coadjuvant in the treatment of obesity and comorbidities. ${ }^{4}$

The beneficial effects of exercise are well known. Evidence from epidemiologic and experimental studies has shown that regular exercise protects against the development and progression of numerous diseases such as heart diseases, diabetes, and obesity. ${ }^{5,6}$ In addition, exercise training directly affects the body composition, preserving or increasing fat-free mass ${ }^{7}$ and stimulating fat mass loss, ${ }^{6}$ in addition to improving inflammatory balance ${ }^{8,9}$ and insulin sensitivity. ${ }^{10}$

The combination of both strategies could therefore enhance the loss and/or maintenance of body fat mass for health or aesthetic purposes, in addition to potentially leading to greater beneficial effects in the treatment of metabolic disorders through improving metabolic profile (insulin sensitivity and lipid profile) and inflammatory balance.

The aim of this paper is to briefly characterize adipose tissue, review the distinct effects of exercise and liposuction, and suggest possible combined effects of both fat-loss strategies in adiposity and metabolism.

\section{Adipose tissue}

Adipose tissue is a remarkable and very efficient energy storage organ that is composed of adipocytes. The adipocyte is a unique cell. It stores triglycerides (TAGs) in a single lipid droplet that accounts for approximately $90 \%$ of the cell mass. ${ }^{3}$ When energy intake is abundant, excess TAGs are stored in adipose tissue to be mobilized during periods of energy deficit. TAGs can be incorporated into adipocytes through the uptake of fatty acids (FAs) from circulating lipoprotein (chylomicrons or very low-density lipoprotein [VLDL]) or can be synthesized during a process called lipogenesis. ${ }^{11}$ In periods of energy deficit, stored TAGs are mobilized in a process called lipolysis that results in the release of free fatty acids (FFAs) into the circulation. These FFAs can be captured by other tissues for oxidation in the mitochondria through the process of $\beta$-oxidation and used as substrate for energy production.,11

The expansion of adipose tissue in response to weight gain seems to depend first on adipocyte hypertrophy. ${ }^{12}$ In fact, the adipocyte has a remarkable storage capacity and is capable of large changes in its TAG volume, with cell sizes ranging from $25 \mu \mathrm{m}$ to $200 \mu \mathrm{m}$ in diameter. ${ }^{5}$ However, as the need for lipid storage increases, preadipocytes are recruited and differentiate into adipocytes in a process called adipogenesis, which consists of adipocyte hyperplasia. ${ }^{11}$

Adipogenesis is the process by which undifferentiated fibroblast-like preadipocytes differentiate into mature adipocytes. ${ }^{12,13}$ It occurs in several stages and can be described as a cascade of gene expression that is regulated by a small set of transcription factors. ${ }^{14,15}$ Two transcription factor families appear to be the key determinants of terminal adipocyte differentiation: peroxisome proliferator-activated receptor gamma (PPAR $\gamma)$ and CCAATT/enhancer-binding proteins (C/EBPs). ${ }^{13,14}$

As cells undergo the differentiation process in response to stimulating signals, the initial stage is the induction of $\mathrm{C} / \mathrm{EBP} \beta$ and $\mathrm{C} / \mathrm{EBP} \delta$ expression. ${ }^{14,15}$ These transcription factors activate the following stage, which includes the increase in the major adipogenic transcription factors $\mathrm{C} / \mathrm{EBP} \alpha$ and PPAR $\gamma$. C/EBP $\alpha$ and PPAR $\gamma$ then induce their own expression in addition to each other's expression, ${ }^{15}$ acting synergistically to generate fully differentiated insulin-responsive adipocytes. ${ }^{14}$ During the terminal stage of differentiation, there is an increase in the protein and mRNA levels of enzymes, receptors, and transporters involved in lipogenesis, lipolysis, and insulin-mediated glucose uptake and of adipokines. ${ }^{12}$ It is important to highlight that although PPAR $\gamma$ is essential and sufficient for induction of the expression of many adipocyte genes, $\mathrm{C} / \mathrm{EBP} \alpha$ is required to confer insulin sensitivity to the adipocyte. ${ }^{13-15}$ Emerging additional factors also play regulatory roles in the process of adipogenesis, such as ADD1/SREBP1, STAT proteins, Kruppel-like factors, wingless INT-1 proteins, cell-cycle proteins, and GATAbinding protein-2 and $-3 .{ }^{12,13,16}$ Whether these factors target similar sets of genes as C/EBPs and PPAR $\gamma$ or enhance or antagonize their effects still remains to be determined. ${ }^{13}$

The processes of adipogenesis, lipogenesis, and lipolysis are tightly regulated by nutrients and neurohumoral signaling in response to the energy needs of the individual, ${ }^{3}$ thus maintaining energy homeostasis. Insulin is the major hormone stimulating lipogenesis and adipogenesis, in addition to inhibiting lipolysis. On the other hand, catecholamines are the most potent regulators of lipolysis in humans, ${ }^{17}$ although glucagon, growth hormone, and thyroid hormones also stimulate lypolysis. ${ }^{3}$

\section{Adipokines and insulin sensitivity}

The remaining $10 \%$ of the adipocyte cell mass has a remarkable secretory ability, synthesizing and releasing many autocrine, paracrine, and endocrine factors called adipokines. ${ }^{18}$ 
A few of these adipokines might not be produced by the adipose tissue itself but by macrophages that have infiltrated the adipose tissues..$^{5}$ Adipocytes also express several receptors that enable them to respond to neurohumoral and hormonal signals. Therefore, adipose tissue constantly communicates with several organs, including the central nervous system (CNS). ${ }^{18}$ Through this dynamic signaling network, adipose tissue and adipokines participate in important biologic processes such as energy intake and energy balance, nutrient metabolism, and the immune system. ${ }^{8,18,19}$

Adipokines such as leptin, adiponectin, tumor necrosis factor (TNF)- $\alpha$, interleukin (IL)-6, and IL-10 play a fundamental role in energy metabolism, insulin sensitivity, and the inflammatory balance ${ }^{20}$ and will be briefly discussed in this review.

Leptin is an $o b$ gene product and is known as the "satiety hormone". Its levels and expression are highly correlated to the amount of body fat mass. ${ }^{17,21,22}$ The central role of leptin is to signal the fat mass status to the CNS. It acts on hypothalamic neurons to inhibit food intake and enhance energy expenditure and sympathetic nervous system (SNS) activity. ${ }^{23}$ Evidence also suggests an important peripheral role of leptin. In addition to stimulating the SNS, leptin impairs the effects of insulin on adipose tissue and increases TNF- $\alpha$ secretion, both of which lead to increased lipolysis. ${ }^{22,24}$ Moreover, it enhances the function and sensitivity of insulin in skeletal muscle by increasing FFAs and glucose oxidation via activation of $5^{\prime}$-adenosine monophosphate-activated protein kinase. ${ }^{22,24,25}$

Leptin mRNA is elevated in subcutaneous adipose tissue (SAT) compared with visceral adipose tissue (VAT), probably because subcutaneous adipocytes are larger than omental adipocytes, and as adipocytes increase in size, leptin mRNA is upregulated. ${ }^{26}$ Other factors also regulate leptin expression, synthesis, and secretion. Insulin, glucose, glucocorticoids, and TNF- $\alpha$ appear to stimulate leptin secretion, whereas sympathetic and adrenergic stimulation, growth hormone, thyroid hormones, androgens, and melatonin appear to reduce leptin levels. ${ }^{3,21}$ Subtle disturbances in the energy balance also affect the expression and synthesis of leptin. An increase or a decrease in energy intake without changes in body weight results in a keen decrease and increase, respectively, in leptin levels within 12 hours. ${ }^{27}$ Thus, leptin can be considered as a sensor of the energy balance. ${ }^{28}$

Adiponectin is synthesized and secreted mostly by the adipose tissue. Its levels are inversely correlated to the amount of body fat mass ${ }^{11}$ and risk of insulin resistance and cardiovascular diseases. ${ }^{3}$ In fact, adiponectin levels are reduced in obese, insulin-resistant, and diabetic individuals and appear to increase after weight and fat loss in obese people. ${ }^{28}$ Its metabolic effects include a reduction of hepatic lipid and glucose synthesis, leading to reduced levels of circulating glucose and FFAs, in addition to increasing glucose uptake and glucose and FA oxidation in the skeletal muscle and adipose tissue. All of these actions will ultimately lead to improved insulin sensitivity. ${ }^{3,19,28}$ Additionally, adiponectin has an anti-inflammatory and an antiatherogenic effect. It reduces the synthesis of proinflammatory cytokines such as TNF- $\alpha$ and C-reactive protein (CRP), enhances vasodilatation, inhibits the adhesion of monocytes to the vascular endothelium, and suppresses the transformation of macrophages into foam cells (the latter are essential steps in the development of vascular diseases). ${ }^{3,19}$

TNF- $\alpha$ is an immunomodulatory and proinflammatory cytokine $^{3}$ that is produced by a variety of cell types. It is produced mainly by cells of the immune system (monocytes, macrophages, and lymphocytes) but also by tumor cells, smooth muscle cells, fibroblasts, and, to a lesser extent, adipocytes. $^{29,30}$ The correlation between plasma TNF- $\alpha$ and adiposity is relatively weak, which suggests that TNF- $\alpha$ produced in adipose tissue acts primarily in a paracrine and autocrine manner. ${ }^{17,31}$ Nevertheless, its levels are higher in obesity and decrease after weight and fat loss, ${ }^{3,17,29}$ and its expression and secretion in adipose tissue appear to be elevated in obese subjects. ${ }^{3,17}$ More importantly, TNF- $\alpha$ is an important inducer of insulin resistance in the liver, adipose tissue, and skeletal muscle. ${ }^{3,29}$ It is likely that TNF- $\alpha$ impairs the activity of insulin via the suppression of insulin signaling and the translocation of glucose transporter 4 (GLUT-4) to the membrane. ${ }^{11,31}$ In addition, it decreases the levels of adiponectin and increases those of cytokines such as IL-6, IL-1, and leptin. ${ }^{31,32}$ In adipose tissue, TNF- $\alpha$ also inhibits lipogenesis and adipogenesis and enhances lipolysis, which increases the amount of FFAs in the circulation. This could also impair the activity of insulin., ${ }^{3,30}$ It has been demonstrated in vitro that TNF- $\alpha$ is a major factor in the regulation of adipocyte number. It inhibits the differentiation of new adipocytes and promotes dedifferentiation or induces apoptosis of existing adipocytes or preadipocytes. ${ }^{31}$ It has been suggested that the production of TNF- $\alpha$ by adipose tissue could be a local regulator of fat cell size and that the overproduction of TNF- $\alpha$ in adipocytes of obese individuals could be a homeostatic mechanism that is designed to limit further increases in adipocyte size. ${ }^{17}$ Altogether, the net effect of TNF- $\alpha$ is to induce insulin resistance, increase lipid mobilization, and facilitate a proinflammatory state. ${ }^{32}$ 
IL-6 is also produced by many cell types, such as monocytes, fibroblasts, and endothelial cells. ${ }^{29}$ However, in contrast to TNF- $\alpha$, IL- 6 plasma levels are proportional to the fat mass and increase in obesity, suggesting that adipose tissue may be an important source of circulating IL-6 levels in the absence of acute inflammation. ${ }^{17,29}$ In fact, adipocytes contribute to approximately $35 \%$ of the circulating IL-6 levels. ${ }^{8}$ IL- 6 synthesis is stimulated by TNF- $\alpha$, and these cytokines have many similar effects. They are both immunomodulatory and proinflammatory cytokines that stimulate lipid mobilization and insulin resistance..$^{29,31}$ In addition, IL-6 may further decrease insulin sensitivity by reducing the secretion of adiponectin. ${ }^{8}$ IL- 6 appears to play a more systemic role than TNF- $\alpha$; it induces hepatic CRP release and has anorectic effects on the hypothalamus, similarly to leptin. ${ }^{31}$ In fact, elevated IL-6 and CRP plasma levels are predictive of the development of diabetes and cardiovascular disease..$^{29,33}$

IL-10 is a potent anti-inflammatory cytokine that is also produced by many cell types, including monocytes, macrophages, and lymphocytes. ${ }^{30} \mathrm{IL}-10$ is a potent inhibitor of the production of proinflammatory cytokines and chemokines implicated and involved in the onset of inflammation. Its antiinflammatory activities rely mostly on the inhibition of IL-1 and TNF- $\alpha$ synthesis from a variety of cell types and on the stimulation of expression of their natural antagonists (IL-1RA and soluble TNF receptor), thus enhancing the synthesis of anti-inflammatory molecules. ${ }^{34}$ IL-10 is also expressed and secreted by adipose tissue, and its circulating levels are elevated in obese subjects ${ }^{30}$ and during acute inflammation, ${ }^{31,35}$ which suggests that IL-10 may act as a feedback mechanism in response to the excess secretion of proinflammatory cytokines such as TNF- $\alpha,{ }^{36,37}$ possibly in an attempt to attenuate its deleterious proinflammatory effects. ${ }^{30}$

\section{Adipose tissue distribution}

There are two main depots of adipose tissue in the body, SAT and VAT, and they differ in anatomic location and metabolic function.

The expression and secretion of adipokines in adipose tissue vary according to the adipocyte size and number and to the adipose tissue depot. ${ }^{3,17,22,29-31}$ IL-6 secretion is higher in VAT than in SAT, ${ }^{17,29,30,38}$ which could partly explain the relationship between abdominal obesity and cardiovascular risk in humans. ${ }^{29}$ On the other hand, adiponectin expression and secretion, as well as leptin expression, ${ }^{17,22,29}$ are higher in SAT than in VAT adipocytes, ${ }^{17,29,30}$ probably due to differences in the fat cell size. The larger the adipocyte, the greater the expression of leptin. ${ }^{22}$ TNF- $\alpha$ appears to be expressed and secreted equally in both depots. ${ }^{17}$

Lipid mobilization and subsequent FFA and glycerol release are modulated by the $\mathrm{SNS}^{17}$ and differ greatly in SAT and VAT. Catecholamines are the most potent regulators of lipid mobilization in adipose tissue via the stimulation of adrenoreceptors $\left(\beta_{1}-, \beta_{2}{ }^{-}\right.$, and $\beta_{3}$-adrenoreceptors) and the inhibition of $\alpha 2$-adrenoreceptors. ${ }^{3,39} \beta$-adrenoreceptors stimulate hormone-sensitive lipase (HSL) and inhibit lipoprotein lipase, which leads to increased lipolysis, whereas $\alpha 2$-adrenoreceptors have the opposite effect. ${ }^{17}$ Insulin, on the other hand, has a lipogenic effect that favors TAG deposition in adipose tissue via the stimulation of adipogenesis, glucose and FFA uptake, and TAG synthesis within adipocytes. In addition, insulin stimulates $\alpha 2$-adrenoreceptors. ${ }^{40}$

Femoral and gluteal subcutaneous adipocytes display a lower lipolytic response to catecholamine than abdominal subcutaneous adipocytes and an even lower response than visceral adipocytes. These differences can be explained by a variation in adrenoreceptor density and sensitivity among these adipocytes. Abdominal SAT shows increased $\beta_{1}$ - and $\beta_{2}$-adrenoreceptors and decreased $\alpha 2$-adrenoreceptors when compared with femoral and gluteal SAT. ${ }^{39}$ VAT adipocytes are even more sensitive than abdominal SAT to catecholamineinduced lipolysis and are less sensitive to insulin activity, presenting a greater number of $\beta_{1^{-}}, \beta_{2}-$, and $\beta_{3}$-adrenoreceptors with enhanced sensitivity. ${ }^{17}$ Thus, VAT is considered to be more metabolically active, and it presents lipolysis rates that are up to $50 \%$ higher than those of SAT. ${ }^{38}$

The enhanced lipolytic activity in VAT may lead to increased FFA levels in the systemic circulation. Because VAT is drained by the portal venal system, increased amounts of VAT may lead to an increased delivery of FFAs to the liver. This could lead to increased VLDL production and secretion, in addition to the induction of changes in insulin signaling that may culminate in increased glucose production due to a decreased inhibition of hepatic glucose output. This creates a favorable environment for the onset of dyslipidemia, glucose intolerance, and hyperinsulinemia. ${ }^{17,41}$ In addition to the effects on the liver, increased FFA levels impair insulin signaling in the skeletal muscle, thus decreasing insulin-mediated glucose uptake and consequently leading to hyperglycemia. ${ }^{38}$ This, in turn, could potentiate glucosestimulated insulin production and therefore contribute to a state of hyperinsulinemia and insulin resistance. ${ }^{41}$

It has been suggested that the distribution of body fat is more important for cardiovascular risk than total adiposity. Upper-body fat, especially fat in the visceral area, 
is independently associated with several risk factors for metabolic and cardiovascular complications (coronary artery disease, hyperinsulinemia, insulin resistance, hypertension, and dyslipidemia). ${ }^{1741-45}$ According to Kral, ${ }^{46}$ SAT, especially gluteofemoral SAT, may function as a "metabolic sink" that accommodates excess energy intake through the uptake of excess FFAs, which could impair glucose uptake and insulin sensitivity. However, according to Kelley et al, ${ }^{38}$ not only VAT but also deep abdominal SAT may have a significant metabolic role. The authors show that, similarly to VAT, abdominal deep SAT displays a robust relation to insulin resistance and other cardiovascular risk factors, such as blood pressure, fasting insulin, and lipids. The authors note, however, that abdominal superficial SAT shows a weak association with insulin resistance, following the pattern of gluteofemoral SAT. ${ }^{38}$ It has also been suggested that upperbody SAT may be the predominant source of circulating FFAs, because SAT is reasonably larger than VAT and is therefore able to release more FFAs into the circulation. ${ }^{17,41}$ However, excess visceral fat is still considered an independent risk factor that links central fat and insulin resistance. This association is partly due to the molecules that are released, such as IL-6, which play a significant role in insulin sensitivity. ${ }^{17}$ Therefore, one could affirm that increased VAT is a very powerful risk factor for the development of cardiovascular diseases, with an even greater risk encountered in the presence of increased deep abdominal SAT.

\section{Liposuction}

Liposuction is the most popular aesthetic surgery performed worldwide. ${ }^{47}$ The Brazilian Society of Plastic Surgery estimates that approximately 92,000 liposuction surgeries are performed every year in Brazil, which represents $20 \%$ of all aesthetic plastic surgeries. In the US, liposuction is also the most frequent aesthetic surgery performed each year. ${ }^{48}$

The American Academy of Cosmetic Surgery ${ }^{49}$ recommends that liposuction should only be indicated for the removal of localized deposits of adipose tissue that do not respond to diet and exercise and should not be indicated for weight loss purposes. Thus, ideal candidates for surgery would be healthy individuals who are in good physical condition (within $30 \%$ of ideal weight). ${ }^{48}$ Prior to liposuction, the physician infuses the body with a determined volume of buffered saline solution. Depending on the volume of this infusion, the surgery is considered a small-volume liposuction $(<5 \mathrm{~L})$ or a large-volume liposuction $(>5 \mathrm{~L}) .{ }^{50}$ Smallvolume liposuction is the most safe and commonly performed procedure in normal to overweight individuals. ${ }^{51}$
Nevertheless, in light of the possible benefits of this surgery on the metabolic profile, large-volume liposuction has frequently been performed in obese people, especially for scientific purposes.

\section{Effects of liposuction on the metabolic profile}

Because adipose tissue is clearly a complex, metabolically active organ, its instant removal by liposuction could directly affect metabolism in obese and nonobese individuals. ${ }^{51}$ In general, studies concerning the metabolic effects of liposuction are controversial.

VAT remains intact during liposuction, in contrast to SAT. Because of the possible beneficial effects of SAT described previously, a few authors have questioned the metabolic safety of liposuction and suggested that the removal of SAT might be detrimental ${ }^{52}$ because it leads to an immediate increase in the proportion of total fat, which is VAT, and this phenomenon may worsen insulin resistance, lipid profile, and other cardiovascular risk factors. ${ }^{53}$ Corroborating this hypothesis, Weber et $\mathrm{al}^{54}$ reported increased insulinemia, triglyceridemia, and hepatic fat content in rats that were fed a hyperlipidic diet 3 months after lipectomy of SAT.

However, most studies in humans have failed to demonstrate detrimental effects of liposuction on metabolism, ${ }^{4,51,53-63}$ thus refuting the aforementioned hypothesis. MartínezAbundis et $\mathrm{al}^{56}$ demonstrated decreased leptin levels but no changes in insulin sensitivity in six obese, healthy women 50 days after abdominal liposuction plus abdominoplasty. Mohammed et $\mathrm{al}^{57}$ evaluated seven obese women at 10, 27, and 208 weeks following a large-volume liposuction. As expected, the authors observed a $25 \%$ decrease in SAT but no changes in VAT, lipid profile, and insulin sensitivity at any time point. Busetto et $\mathrm{al}^{55}$ observed lower levels of leptin but no changes in resistin, IL- 6 , TNF- $\alpha$, and FFA levels at 28 days and 6 months after surgery in eight morbidly obese diabetic or glucose-intolerant subjects. An improvement in insulin sensitivity was observed 28 days after surgery, but it was no longer significant after 6 months. Klein et $\mathrm{al}^{58}$ studied 15 women with central obesity (waist circumference $>100 \mathrm{~cm}$ ), of which eight demonstrated normal glucose tolerance and seven had type 2 diabetes. Three months after a large-volume abdominal liposuction, despite the reduction in body weight, abdominal and body fat mass, and leptin levels, there was no change in insulin sensitivity. In addition, there were no changes in fasting glycemia; in TNF- $\alpha$, IL-6, adiponectin, and CRP levels; or in cardiovascular risk factors such as blood pressure and lipid profile. The authors stated that liposuction 
should not be considered as a clinical treatment for obesity, because it does not appear to have beneficial effects on the metabolic profile due to the decreases in body weight and body fat induced by diet and exercise. It must be noted that exercise- or diet-induced loss of body weight and body fat leads to a decrease in both SAT and VAT, ${ }^{38}$ which is associated with cardiovascular risk factors. In fact, experimental studies have shown that the surgical removal of VAT is associated with an immediate improvement of insulin resistance, ${ }^{64}$ thus validating the benefits of reducing fat stored in this depot.

As described previously, and similarly to VAT, deep abdominal SAT is also strongly related to insulin resistance and other cardiovascular risk factors. ${ }^{38} \mathrm{Up}$ to $50 \%$ of SAT is located in the deep layer and, during abdominal liposuction, this is the predominant removed tissue. ${ }^{50,51}$ Corroborating this hypothesis, the aforementioned studies reported no changes, ${ }^{55-58}$ and many other studies have reported improvements in one or more cardiovascular risk factors 3 weeks to 6 months after liposuction. ${ }^{4,51,53,59-63}$

Davis et $\mathrm{al}^{51}$ evaluated the effects of small-volume abdominal liposuction in 15 normal to overweight healthy women. One month after surgery, no changes in leptin, adiponectin, IL-6, and TNF- $\alpha$ levels were detected in either group. However, there was a significant decrease in fast insulinemia in both groups, but only the obese group showed a significant improvement in insulin sensitivity. Six months after a small-volume abdominal liposuction in 30 healthy obese women, Giugliano et $\mathrm{al}^{60}$ observed improved insulin sensitivity; diminished levels of IL-6, IL-18, TNF- $\alpha$, and CRP; and increased levels of adiponectin and HDL-cholesterol in the absence of weight loss. Robles-Cervantes et $\mathrm{al}^{59} \mathrm{dem}-$ onstrated no changes in body weight, fasting insulinemia, and insulin sensitivity measured by homeostasis model assessment-insulin resistance (HOMA-IR) at 21 days after a small-volume abdominal liposuction in 15 healthy normalweight women. However, a decrease in fasting glycemia, total cholesterol levels, and estimated insulin secretion measured by HOMA\% was observed. Fasting glycemia was reduced and insulin sensitivity was improved 1 month after a largevolume liposuction in 12 healthy obese women. ${ }^{61} \mathrm{D}^{\prime}$ Andrea et $\mathrm{al}^{4}$ reported improved insulin sensitivity; reduced levels of fasting insulin, glucose, TAGs, total cholesterol, leptin, TNF- $\alpha$, resistin, and IL-6; reduced blood pressure; and increased adiponectin levels in 123 healthy obese women at 90 days after a large-volume liposuction. Insulin sensitivity was improved, but no changes in the lipid profile were detected at 4 months after a large-volume liposuction in 14 healthy overweight to obese women. ${ }^{53}$ On the other hand,
Ybarra et $\mathrm{al}^{62}$ demonstrated an improved lipid profile but no changes in insulin sensitivity or CRP and adiponectin levels in 18 healthy normal to slightly overweight women at 4 months after a large-volume abdominal liposuction. Rizzo et $\mathrm{l}^{63}$ observed improved insulin sensitivity; decreased levels of IL-6, TNF- $\alpha$, leptin, and resistin; and increased levels of IL-10 and adiponectin in 20 healthy obese women at 40 days after abdominal dermolipectomy. Finally, Hong et al ${ }^{65}$ reported a significant improvement in the lipid profile but no changes in cytokine levels or insulin sensitivity at 2 months after surgery in 11 normal-weight healthy subjects.

Taken together, these studies have reported diverse yet mostly beneficial effects of liposuction on one or more cardiovascular risk factors (insulin sensitivity, lipid profile, and pro- and anti-inflammatory cytokines). Explanations for the diversity of these results may include differences in the follow-up time after surgery, in the methods used to test for insulin sensitivity, and mainly in the characteristics of the subjects. Most of the studies that evaluated morbidly obese people $\left(\right.$ BMI $\left.>35 \mathrm{~kg} / \mathrm{m}^{2}\right)$ did not show significant improvements in the metabolic profile regardless of the follow-up time after surgery (50 days to 208 weeks). ${ }^{55,57,58}$ One hypothesis is that the decrease in abdominal SAT, although substantial, may have been insufficient enough to overcome the negative effects of the excess visceral fat on insulin sensitivity, cytokine production, and lipid profile in these subjects. Consistent with this hypothesis, most studies evaluating overweight to slightly obese individuals observed significant improvements in insulin sensitivity ${ }^{4,51,53,59-61,63}$ and cytokine production, ${ }^{4,60,63}$ although they failed to observe improvements in the lipid profile, ${ }^{53,59,61}$ which indicated that the reduction of abdominal SAT in these subjects was effective in surpassing the effects of excess VAT on the metabolic profile. Finally, the few studies that evaluated normal-weight individuals did not demonstrate significant effects on the metabolic profile. In summary, these studies do not support a significant role for liposuction as a treatment for obesity and its comorbidities in morbidly obese subjects. Nevertheless, the results support the metabolic safety of liposuction for aesthetic purposes in normal to overweight or even slightly obese people, who represent the majority of people interested in this type of plastic surgery for cosmetic purposes..$^{50}$

\section{Effects of liposuction on adiposity and body fat distribution}

According to the "liposthatic theory" proposed by Kennedy, ${ }^{66}$ a long-term energy balance is achieved via accurate feedback systems that regulate adipose tissue depots. Thus, if total 
body fat is constantly monitored, an instant decrease in body fat through liposuction could trigger feedback systems that might favor the recovery of body fat through a decrease in energy expenditure and/or an increase in energy intake. ${ }^{67}$

In many species, when body fat is surgically removed, it is recovered within a period of weeks to months, ${ }^{54,67-71}$ usually due to a compensatory adipose tissue expansion at intact depots ${ }^{54,68,69}$ rather than regrowth of the fat mass in aspirated depots. ${ }^{67}$ Many studies ${ }^{54,68-70}$ reported no visible regrowth of fat in the lipectomized depot but reported similar levels of total body fat in lipectomized and sham-operated wild-type or genetically obese animals as early as 30 days $^{68}$ to $12^{54}$ weeks to 16 weeks after lipectomy, ${ }^{69,70}$ which indicated that the lipectomized animals compensated for the removal of fat. In animal models, the ability of fat pads to exhibit compensation is not uniform and depends on the fat pad that is excised. ${ }^{54,69}$ In addition, the type of compensation may occur in a fat pad-specific manner. ${ }^{67,69,72}$ Internal fat depots appear to compensate via an increase in the size of fat cells (hypertrophy) and subcutaneous fat pads by an increase in the number of fat cells (hyperplasia). Giese et $\mathrm{al}^{53}$ emphasized the importance of evaluating a possible fat mass redistribution toward the visceral cavity after liposuction, which could enhance cardiovascular risk.

Most human studies have not assessed patients for regrowth or compensation of body fat after liposuction. ${ }^{67}$ Nonetheless, the few studies that have made this attempt show controversial results. Rinomhota et $\mathrm{al}^{73}$ observed a substantial increase in body weight $(+5 \%-6 \%$ of the presurgery weight) and total body fat $(+16 \%$ of the presurgery fat mass) in overweight to obese women 18 months after a large-volume liposuction plus abdominoplasty surgery. In contrast, 2 months after abdominal liposuction or abdominoplasty in seven nonobese women, Lambert et $\mathrm{al}^{74}$ reported no changes in the regional fat distribution in nonoperated areas or in the fat cell size in femoral (nonoperated area) and abdominal regions (operated area). In addition, no changes were observed in food intake or resting energy expenditure (RER). Busetto et $\mathrm{al}^{55}$ also showed no evidence for adipose tissue regain or redistribution in obese women at 6 months after surgery, despite a decrease in RER and in leptin levels. Fat regain may have been detected in a longer-term follow-up. A period longer than 6 months may be necessary to induce substantial compensatory responses in humans, which differs from the findings reported for experimental studies, probably due to metabolic differences among species.

Leptin may be a major inducer of the possible compensatory responses of adipose tissue at intact depots or regrowth of the fat mass at aspirated depots. Many studies have reported significant decreases in leptin levels as early as 1 day and up to 3 months after liposuction. ${ }^{4,55,58,63,75}$ This response is expected because SAT adipocytes, the primary source of leptin in humans, ${ }^{22,26}$ are removed during liposuction. As described earlier, leptin acts on hypothalamic neurons to inhibit food intake and to enhance energy expenditure and SNS activity. ${ }^{23}$ It also has peripheral effects, such as increased lipolysis and elevated glucose and FFA oxidation in skeletal muscle. ${ }^{22,24,25}$ Thus, the instant decrease in leptin levels after liposuction could trigger compensatory responses that enhance food intake and decrease energy expenditure, which would facilitate weight and fat regain. However, it is important to emphasize that leptin is not likely to be the only substance that affects the regulation of body fat, as serum factors other than leptin also appear to stimulate adipogenesis, ${ }^{69}$ and compensatory responses of fat have been reported in rats carrying a leptin receptor deficiency. ${ }^{70}$

Nevertheless, it is logical to expect a positive energy balance if there is any compensatory growth of adipose tissue following liposuction. Decreases in body weight and fat through caloric restriction lead to a decrease in the RER and an enhancement in appetite and metabolic efficiency that might help reverse weight and fat loss in humans ${ }^{74,76}$ and in experimental studies. ${ }^{77-79}$ Thus, it would be expected that the observed recovery of body fat after lipectomy in experimental studies could be facilitated by the same mechanisms. Animal experiments show that lipectomy does not lead to increases in food intake. ${ }^{54,67,69,79}$ Thus, it is likely that decreases in energy expenditure and/or increases in metabolic efficiency may provide the extra energy needed for compensatory fat deposition in animals after lipectomy. ${ }^{67,77}$ Previous studies in nonobese women who underwent either large- or smallvolume liposuction ${ }^{53,74}$ support an absence of RER or changes in metabolic efficiency after liposuction in this population, in contrast to the results reported for obese subjects..$^{55}$ There is evidence that the fat-free mass is the major determinant of the resting metabolic rate, whereas the fat mass is a significant factor only in obese subjects. ${ }^{80}$ Thus, obese subjects may present stronger adaptive responses that favor body fat regain after liposuction through the decrease of RER.

It has been affirmed that presurgery body fat is an important factor in determining weight and fat gain following surgery and that overweight and obese individuals are more prone to the recovery of body fat than eutrophic people, ${ }^{68,73}$ although to our knowledge no studies have directly addressed this issue. Nevertheless, Rinomhota et $\mathrm{al}^{73}$ reported greater weight and body fat regain in subjects with a higher presurgery 
weight at 18 months after a large-volume liposuction plus abdominoplasty surgery. Experimental studies seem to support this hypothesis. Harris et $\mathrm{al}^{70}$ reported that all intact fat pads tended to increase at 16 weeks after lipectomy in wildtype and ob/ob obese mice, which might have accounted for the recovery of total body fat in both genotypes; however, this difference only reached significance for the visceral fat pads in the obese mice. Bueno et $\mathrm{al}^{68}$ reported a significant increase in the carcass lipogenesis rate and in the percentage of small-area adipocytes at the site of fat removal at 30 days after lipectomy of retroperitoneal and epididymal fat pads in monosodium-glutamate obese animals but not in control animals. The authors suggested that the increased metabolic efficiency observed in these animals stimulated the differentiation of adipocytes, thus favoring reposition of the lost adipocytes and restoration of the fat pad removed.

\section{Exercise \\ Effects of exercise on the metabolic profile}

Physiologic changes occur to increase lipid utilization during exercise. Enhanced sympathetic activity increases catecholamine levels, which activate HSL via $\beta$-adrenoreceptor stimulation and suppress insulin, reducing its inhibitory effects on HSL. ${ }^{5}$ These changes stimulate lipolysis and consequently lead to increased glycerol and circulating levels of FFAs, which may be used as substrates for energy production. ${ }^{81}$ In addition, an increase in the catecholaminestimulated lipolytic responsiveness of adipocytes seems to occur, which further increases lipid mobilization during exercise..$^{82,83}$

During low- to moderate-intensity exercise (40\%-65\% VO2max), lipids are the predominant source of energy. ${ }^{82}$ Nevertheless, during high-intensity exercise, lactate accumulation inhibits HSL activity and thus reduces the mobilization of adipocyte lipids and favors the use of glucose and glycogen as sources of energy production in muscle. ${ }^{84}$

Chronic exercise training also results in the following physiologic adaptations that enhance lipid utilization during exercise: i) higher intramuscular TAG hydrolysis, ${ }^{85}$ ii) a higher lipolytic capacity of adipocytes in response to increased levels of catecholamine due to a greater efficiency or stimulation of the $\beta$-adrenergic pathway and a diminished inhibition of lipolysis by $\alpha$-adrenoreceptors, ${ }^{5}$ and iii) an increased proportion of energy derived from FA oxidation during exercise ${ }^{82}$ due to an enhanced muscle lipid oxidation capacity. ${ }^{83}$ The latter adaptation is facilitated by increased capacities for FA uptake by muscle cells, which is likely due to the higher contents of membrane FA transport proteins such as FA-binding protein and FA translocase (CD36) and subsequent mitochondrial transport and $\beta$-oxidation, probably caused by a higher content of the mitochondrial transporter carnitine palmitoyltransferase I. ${ }^{86}$

It has been established that exercise acutely improves glucose uptake via increased insulin sensitivity and via muscle contraction in an insulin-independent manner. Both mechanisms have additive effects and stimulate glucose uptake via separate pathways. ${ }^{87,88}$ Muscle contraction stimulates glucose uptake through the following proposed mechanisms: increased release of $\mathrm{Ca}^{2+}$ from the sarcoplasmic reticulum, which results in the activation of $\mathrm{Ca}^{2+} /$ calmodulin-dependent protein kinase II (CaMKII); activation of the adenosine monophosphate (AMP)-activated protein kinase pathway (AMPK) due to a decrease in adenosine triphosphate and an increase in AMP; activation of mitogen-activated protein kinase $38 ;^{87,89}$ and phosphorylation of Akt/protein kinase B. ${ }^{90}$ These mechanisms will ultimately increase the translocation of GLUT-4 from intrasarcolemmal pools/vesicles to the cell surface ${ }^{91}$ via a mechanism(s) that is not completely understood. Therefore, the immediate effects of exercise on glucose uptake appear to rely primarily on increased GLUT-4 trafficking. ${ }^{90}$ In addition, it has been suggested that insulin sensitivity remains elevated immediately after exercise, thus improving glucose uptake in an insulin-dependent manner for up to 48 hours after exercise cessation. ${ }^{90}$ This phenomenon is probably due to a higher and more responsive translocation of GLUT-4 to the cell surface ${ }^{87,91}$ and to endurance exerciseinduced glycogen depletion. ${ }^{87}$

Exercise training also improves glucose uptake via insulin-mediated mechanisms, thus enhancing insulin sensitivity and activity. ${ }^{87,90}$ The enhanced activity of insulin after exercise training may be associated with the following: i) increased expression of GLUT-4 mRNA and protein in skeletal muscle; ${ }^{87}$ ii) enhanced postreceptor insulin signaling at the level of phosphatidylinositol-3-kinase activity, which may lead to enhanced GLUT-4 translocation; ${ }^{91}$ iii) upregulation of AMPK activity, which enhances glucose uptake and stimulates FA oxidation; ${ }^{90}$ and iv) increased oxidative capacity of skeletal muscle via upregulation of the proteins involved in mitochondrial biogenesis, such as PPAR $\gamma$ coactivator. ${ }^{92}$ It has been suggested that enhanced whole-body lipid oxidation is a strong predictor of insulin sensitivity. ${ }^{93}$ Thus, if exercise training increases the proportion of lipids targeted for oxidation, ${ }^{82}$ it will ultimately lead to improved insulin sensitivity. ${ }^{33}$ 
Exercise may also affect insulin indirectly through its effects on adipokines and inflammatory cytokines. However, in general, studies investigating the effects of exercise training on adipokine and cytokine levels and expression are quite controversial.

The majority of studies have reported either no change ${ }^{31,94-96}$ or a reduction in leptin levels ${ }^{97-102}$ after chronic exercise training, and these results have been attributed primarily to the capacity of exercise to induce a loss of fat mass. ${ }^{97,98,100,102}$ Conversely, a few studies have demonstrated a reduction in leptin levels and/or expression regardless of any changes in adiposity. ${ }^{99,101}$ These results suggest that there may be factors beyond adiposity that regulate leptin levels and expression after endurance training, among which adipokines are strong candidates. In addition, it has been proposed that regular exercise may lead to a "resetting" of leptin levels, such that a lower concentration of leptin can be maintained with a certain body fat content due to possible improvements of the activity and sensitivity of leptin in the hypothalamus. ${ }^{103}$

Studies on the effect of aerobic training on plasma adiponectin have also showed conflicting results. Most studies have reported no changes in adiponectin levels, ${ }^{102,104-108}$ despite improved insulin sensitivity ${ }^{102,104,105,108}$ and changes in body weight, ${ }^{102,105-108}$ whereas other studies have demonstrated increased adiponectin levels and insulin sensitivity either with no changes in body weight ${ }^{109,110}$ or with weight loss. ${ }^{110-112}$ These heterogeneous results may be explained by the diversity of subject characteristics (body composition and metabolic profile) and the type of intervention used (exercise only or diet plus exercise). In addition, exercise intensity also appears to affect adiponectin in different ways. Moderate-to-high-intensity aerobic or resistance exercise training appears to increase adiponectin levels, in contrast to low-intensity exercise, which suggests a dose-response relationship. ${ }^{113}$ More importantly, many studies have shown that improvements in insulin sensitivity after exercise training may occur in the absence of changes in adiponectin. ${ }^{102,104,105,108,114}$ It is likely that the influence of other substances that are modified by exercise training and affect adiponectin synthesis and secretion, such as TNF- $\alpha$ and IL-6, may have different effects on adiponectin levels according to the type of intervention. ${ }^{102}$

\section{The anti-inflammatory effects of exercise}

It has been well established that several proinflammatory and anti-inflammatory cytokines increase markedly after exercise in a dose-response manner. The higher the duration, intensity, and amount of muscle mass recruited, the greater the increase. ${ }^{9,115}$ However, this increase differs from that of severe infections, in which the cytokine cascade consists of an initial increase in TNF- $\alpha$ and IL- $1 \beta$ followed by increases in IL-6, IL-1ra, aTNF-R, and IL-10. ${ }^{116}$ IL-6 is the first cytokine to increase in an exponential fashion (up to 100-fold) in response to exercise, followed by modest increases by one- to two-fold of TNF- $\alpha$ and IL-1. ${ }^{115,117}$ This inflammatory response is then counterbalanced by an increase in IL-1ra and IL-10, which are anti-inflammatory cytokines. ${ }^{117,118}$ As described earlier, IL-10 is a potent inhibitor of IL-1 and TNF- $\alpha$ production, and it has been postulated that IL-10 is responsible for orchestrating the anti-inflammatory reaction. ${ }^{177}$ Studies have demonstrated that IL- 6 is responsible for the increase in anti-inflammatory cytokines (IL-10 and IL-1 ra) after exercise, and it also inhibits the synthesis of TNF- $\alpha$ and IL- $1,{ }^{118}$ thus inducing an anti-inflammatory milieu. ${ }^{9}$

It has been suggested that regular exercise training may exert a chronic anti-inflammatory effect that is potentially due to the repeated anti-inflammatory responses elicited by each acute bout of exercise. ${ }^{117}$ However, a link between the acute and chronic effects of exercise has not yet been established.

Epidemiologic studies have reported a negative association between the amount of regular physical activity and the levels of IL- 6 and TNF- $\alpha .{ }^{117}$ Interventional studies also support this relationship, although the results are less consistent.

A few studies have reported no changes in IL- 6 and TNF- $\alpha$ levels after exercise training. ${ }^{102,104,106,109,112,119}$ The majority of studies, however, have reported a decrease in IL-6, ${ }^{11,120-122}$ TNF- $\alpha,{ }^{123-125}$ or both. ${ }^{126-128}$ It has been proposed that a weight loss of $10 \%$ is associated with a marked improvement in the metabolic abnormalities associated with obesity, including circulating inflammatory markers. ${ }^{8}$ In addition, overweight to obese people may present low-grade inflammation due to an excess fat mass ${ }^{126}$ and are likely to benefit more from weight loss compared with normal-weight subjects. Giannopoulou et $\mathrm{al}^{104}$ reported greater decreases in IL-6 levels in subjects who demonstrated the highest basal IL-6 levels. Most of the studies that reported decreased TNF- $\alpha$ and/or IL-6 levels after training evaluated overweight to obese people and used diet plus exercise as interventions. ${ }^{102,111,121,122,125-130}$ The weight losses in these studies were substantial (7\%-15\%), which might explain the positive results. If IL- 6 and TNF- $\alpha$ are highly expressed and secreted from adipose tissue, weight loss and fat mass loss would lead to significant decreases in these cytokine levels. The isolated effects of exercise, however, are much less consistent. Only a few studies have evaluated the effects of exercise training without diet on the levels 
of IL-6 and TNF- $\alpha,^{104,109,123,124}$ and all but one ${ }^{119}$ evaluated overweight to obese subjects. These studies reported a weight loss that did not exceed 5\% (3 kg), which is expected because exercise training per se does not induce a considerable energy deficit that could lead to substantial weight loss. ${ }^{131}$ The lack of significant weight loss in these studies and the different types of exercise used may explain the inconsistent results. Four studies reported no change, ${ }^{102,104,119}$ and two studies reported a decrease in TNF- $\alpha$ levels. ${ }^{123,124}$ Thus, the combination of exercise training and a hypocaloric diet shows more consistent results for the reduction of markers of inflammation than does exercise or even diet alone in overweight to obese subjects. However, the independent effect of exercise training on cytokine production from different cell types within adipose tissue requires further investigation. ${ }^{114}$

To our knowledge, no studies in humans have evaluated the effects of exercise on IL-10 levels. However, one experimental study has recently demonstrated that the mesenteric adipose tissue of endurance-trained rats showed an increase in TNF- $\alpha$ content and an even greater increase in IL-10 content in comparison with sedentary rats. ${ }^{37}$ The authors suggested that increased TNF- $\alpha$ is likely to function as a modulator of lipid metabolism by increasing lipolysis in adjacent tissues and that increased IL-10 may block the potentially deleterious inflammatory effects caused by TNF- $\alpha$. Thus, the increased IL-10/TNF- $\alpha$ ratio after exercise training may favor the onset of an anti-inflammatory environment in adipose tissue, which represents one of the possible mechanisms through which exercise may exert its anti-inflammatory effects.

Future studies should evaluate the effects of exercise training with or without dieting on proinflammatory and antiinflammatory levels to determine the inflammatory balance rather than the inflammatory cytokine status alone. Even in the absence of changes in proinflammatory cytokines, an increase in anti-inflammatory cytokine levels may result in an anti-inflammatory environment. Costa Rosa ${ }^{132}$ has elegantly suggested the use of "exercise as a complementary strategy in the treatment of chronic diseases", corroborating the finding that regular exercise appears to protect against diseases associated with low-grade systemic inflammation, such as most chronic diseases. ${ }^{8}$

\section{Effects of exercise on body fat distribution}

Previous studies have consistently shown that without any dietary restrictions, exercise training has a modest effect on weight and fat loss, ${ }^{6,7,133-135}$ whereas resistance exercise training may even induce increases in body weight through elevations in the fat-free mass. ${ }^{7,134,135}$ One exercise session with a duration of 60-90 minutes will lead to the oxidation of a very small amount of fat (approximately 50-75 $\mathrm{g}$ at the most), which has an obviously feeble effect on weight loss. ${ }^{81}$ However, if energy intake remains stable, aerobic exercise training could have a substantial effect on adiposity over a prolonged period. ${ }^{81}$ Furthermore, there seems to be a preferential reduction in VAT and abdominal SAT rather than changes in gluteofemoral SAT ${ }^{136,137}$ in response to exercise training-induced weight loss. Although it is clear that a greater amount of weight results in the reduction of more visceral fat, even in the absence of weight loss, ${ }^{138-141}$ exercise training may lead to significant reductions in VAT.

As described earlier, the capacity for TAG mobilization of adipose tissue varies according to its location. ${ }^{6,17}$ Abdominal adipocytes, especially visceral adipocytes, are more sensitive and responsive to the lipolytic effect of catecholamines than gluteofemoral $\mathrm{SAT}^{5}$ due to the number and sensitivity of $\beta$ - and $\alpha$-adrenoreceptors. Thus, because exercise greatly enhances sympathetic-induced catecholamine levels, repeated bouts of exercise could lead to consistent, preferential lipid mobilization in abdominal adipose tissue, especially VAT, as opposed to gluteofemoral SAT, thus resulting in decreased abdominal fat and sustained SAT. ${ }^{6,133}$

Epidemiologic studies have demonstrated an inverse relationship between training status and the degree of upper-body fat. ${ }^{5,140}$ More importantly, evidence from interventional studies support exercise as an effective intervention for reducing abdominal fat, especially visceral fat, in overweight or obese individuals. ${ }^{140}$ However, it is important to note that pretraining weight is a strong determinant of exercise-induced changes in abdominal fat, ${ }^{6}$ as most studies have reported a reduction of abdominal fat in overweight and obese subjects but not in nonobese subjects. ${ }^{140}$ Thus, if excess upper-body fat, especially in the visceral region, has a greater association with several cardiovascular risk factors and diseases compared with excess lower-body fat, ${ }^{17,41,42,44,45}$ exercise training may be considered a very important nonpharmacologic treatment for obesity, in part by altering the distribution of body fat toward lower-body regions.

\section{Liposuction and exercise training}

Liposuction and exercise appear to directly affect metabolism in similar ways, which suggests a possible interaction between these two strategies. Nevertheless, there is one main difference between them: liposuction surgery decreases SAT exclusively, whereas exercise training enhances lipid metabolism in SAT but also in VAT. Assuming that the 
immediate liposuction-induced increase in the VAT/SAT ratio might be detrimental to metabolism,,$^{53}$ exercise training might be a prime strategy to block or reverse these possible deleterious effects due to its ability to reduce VAT. ${ }^{5,6}$

However, the aforementioned hypothesis is very unlikely because most studies in humans have failed to demonstrate detrimental effects of liposuction on metabolism. ${ }^{4,51,53,55-63}$ During liposuction, not only the abdominal superficial SAT layer but also the deep SAT layer is removed, and the latter is strongly related to insulin resistance and other cardiovascular risk factors. ${ }^{38}$ In accordance, most studies have reported either no change ${ }^{55-58}$ or improvements in one or more cardiovascular risk factors after liposuction. ${ }^{4,51,53,59-63}$ Therefore, in light of the positive effects on insulin sensitivity and the inflammatory balance, physical exercise training could have an additive or even a synergistic effect with liposuction on the metabolic profile.

Finally, animal studies have demonstrated that when body fat is surgically removed, it is recovered within a period of weeks to months, ${ }^{54,67-70}$ usually due to compensatory adipose tissue expansion at intact depots ${ }^{54,68,69}$ rather than regrowth of the fat mass at aspirated depots. ${ }^{67}$ According to the "liposthatic theory" proposed by Kennedy, ${ }^{66}$ an instant decrease in body fat through liposuction could trigger feedback systems that might favor the recovery of body fat through a decrease in energy expenditure and/or an increase in energy intake. According to animal ${ }^{67,77}$ and human studies,${ }^{55}$ it is likely that decreases in energy expenditure and/or increases in metabolic efficiency may provide the extra energy needed for compensatory fat deposition following fat removal. ${ }^{67,77}$ Regular exercise training increases the total energy expenditure and preserves or even increases the fat-free mass, ${ }^{7}$ which could prevent the liposuction-induced decrease in energy expenditure and enhance lipid mobilization and oxidation. ${ }^{6}$ Thus, exercise training associated with liposuction could attenuate or even block the possible compensatory fat deposition in intact depots or regrowth of the fat mass.

To our knowledge, no human studies (and only one experimental study) have attempted to evaluate the effects of liposuction associated with exercise training. ${ }^{142}$ As expected, the authors reported that exercise training attenuated the increased lipogenesis rate and thus impaired the restoration of adipose tissue observed in lipectomized sedentary animals. Further studies are necessary to confirm these results in humans.

\section{Conclusion}

Liposuction is the most popular aesthetic surgery performed worldwide. ${ }^{47}$ In general, studies investigating the metabolic effects of liposuction are controversial, and most of the studies performed in humans have reported either no change $\mathrm{e}^{55-58}$ or improvements in one or more cardiovascular risk factors. ${ }^{4,51,53,59-63}$ In addition, animal studies have shown that when body fat is surgically removed, it is recovered within a period of weeks to months, ${ }^{54,67-70}$ but the few studies performed in humans have demonstrated inconsistent results.

Chronic exercise training induces physiologic adaptations that enhance lipid oxidation during exercise and improve insulin sensitivity and inflammatory balance. It also results in an increased total energy expenditure, a preserved or increased fat-free mass, ${ }^{7}$ and reduced abdominal fat, ${ }^{6}$ especially visceral fat, in overweight or obese individuals. ${ }^{140}$

Thus, one could suggest that the association of exercise training with liposuction could, first, attenuate or even block the possible liposuction-induced compensatory fat deposition in intact depots or regrowth of the fat mass and, second, exert an additive or even a synergistic effect with liposuction, improving insulin sensitivity and the inflammatory balance, which would lead to an improvement of cardiovascular risk factors.

Thus, one could suggest that liposuction and exercise are safe and effective strategies for fat loss that could be associated with better results either for aesthetic purposes or for the treatment of metabolic disorders. Furthermore, studies in humans regarding the interaction of these two fat loss interventions on metabolism and adiposity are needed to confirm the positive effects of exercise reported in animals after partial lipectomy. ${ }^{142}$

\section{Disclosure}

The authors report no conflicts of interest.

\section{References}

1. Flynn TC, Coleman WP, Field LM, et al. History of liposuction. Dermatol Surg. 2000;26(6):515-520.

2. Klein JA. The tumescent technique for liposuction surgery. Am J Cosmet Surg. 1987;4:263-267.

3. Fonseca-Alaniz MH, Takada J, Alonso-Vale MIC, Lima FB. Adipose tissue as an endocrine organ: from theory to practice. J Pediatr. 2007; 83(5 Suppl):S192-S203.

4. D'Andrea F, Grella R, Rizzo MR, et al. Changing the metabolic profile by large-volume liposuction: a clinical study conducted with 123 obese women. Aesth Plast Surg. 2005;29:472-478.

5. Nicklas BJ. Effects of endurance exercise on adipose tissue metabolism. Exerc Sport Sci Rev. 1997;25:77-103.

6. Hansen D, Dendale P, Berger J, et al. The effects of exercise training on fat-mass loss in obese patients during energy intake restriction. Sports Med. 2007;37(1):31-46.

7. Vortruba SB, Horvitz MA, Schoeller DA. The role of exercise in the treatment of obesity. Nutrition. 2000;16:179-188.

8. Esposito K, Giugliano G, Scuderi N, Giugliano D. Role of adipokines in the obesity-inflammation relationship: the effect of fat removal. Plast Reconstr Surg. 2006;118(4):1048-1059. 
9. Fischer CP, Plomgaard P, Hansen AK, et al. Endurance training reduces the contraction-induced interleukin- 6 mRNA expression in human skeletal muscle. Am J Physiol Endocrinol Metab. 2004; 1189:1194.

10. Pereira LO, Lancha AH Jr. Effect of insulin and contraction up on glucose transport in skeletal muscle. Prog Biophys Mol Biol. 2004; 84(1):1-27.

11. Trujillo ME, Scherer PE. Adipose tissue-derived factors: impact on health and disease. Endocr Ver. 2006;27(7):762-778.

12. Gregoire FM. Adipocyte differentiation: from fibroblast to endocrine cell. Exp Biol Med Vol. 2001;226(11):997-1002.

13. Lefterova MI, Lazar MA. New developments in adipogenesis. Trends Endocrinol Metab. 2009;20(3):107-114.

14. Camp HS, Ren D, Leff T. Adipogenesis and fat-cell function in obesity and diabetes. Trends Mol Med. 2002;8(9):442-447.

15. MacDougald OA, Mandrup S. Adipogenesis: forces that tip the scale. Trends Endocrinol Metab. 2002;13(1):5-11.

16. Rangwala SM, Lazar MA. Transcriptional control of adipogenesis. Апnи Ver Nutr. 2000;20:535-559.

17. Wajchenberg BL. Subcutaneous and visceral adipose tissue: their relation to the metabolic syndrome. Endocr Rev. 2000;21(6):697-738.

18. Kershaw EE, Flier JS. Adipose tissue as an endocrine organ. $J$ Clin Endocrinol Metab. 2004;89:2548-2556.

19. Trayhurn P, Beattie JH. Physiological role of adipose tissue: white adipose tissue as an endocrine and secretory organ. Proc Nutr Soc. 2001;60(3):329-339.

20. Carvalho M, Colaço A, Fortes ZB. Cytokines, endothelial dysfunction, and insulin resistance. Arq Bras Endocrinol Metabol. 2006;50(2): 304-312.

21. Koerner A, Kratzsch J, Kiess W. Adipocytokines: leptin-the classical, resistin-the controversial, adiponectin-the promising, and more to come. Best Pract Res Clin Endocrinol Metab. 2005;19(4): $525-546$.

22. Margetic S, Gazzola C, Pegg GG, Hill RA. Leptin: a review of its peripheral actions and interactions. Int J Obes. 2002;26:1407-1433.

23. Niswender KD, Baskin DG, Schwartz MW. Insulin and its evolving partnership with leptin in the hypothalamic control of energy homeostasis. Trends Endocrinol Metab. 2004;15(8):362-369.

24. Zhang F, Chen Y, Heiman M, Dimarchi R. Leptin: structure, function and biology. Vitam Horm. 2005;71:345-372.

25. Yildiz BO, Haznedaroglu IC. Rethinking leptin and insulin action: therapeutic opportunities for diabetes. Int J Biochem Cell Biol. 2006; 38(5-6):820-830.

26. Montague CT, Prins JB, Sanders L, et al. Depot-related gene expression in human subcutaneous and omental adipocytes. Diabetes. 1998;47: 1384-1391.

27. Kolaczynski JW, Ohannesian J, Considine RV. Response to leptin to short-term and prolonged overfeeding in humans. J Clin Endocrinol Metab. 1996;81:4162-4165.

28. Meier U, Gressner AM. Endocrine regulation of energy metabolism: review of pathobiochemical and clinical chemical aspects of leptin, ghrelin, adiponectin, and resistin. Clin Chem. 2004;50(9):1511-1525.

29. Bastard JP, Maachi M, Lagathu C, et al. Recent advances in the relationship between obesity, inflammation, and insulin resistance. Eur Cytokine Netw. 2006;17(1):4-12.

30. Juge-Aubry CE. Adipose tissue: a regulator of inflammation. Best Pract Res Clin Endocrinol Metab. 2005;19(4):547-566.

31. Coppack SW. Pro-inflammatory cytokines and adipose tissue. Proc Nutr Soc. 2001;60(3):349-356.

32. Do Nascimento CO, Hunter L, Trayhurn P. Regulation of haptoglobin gene expression in 3T3-L1 adipocytes by cytokines, catecholamines, and PPARgamma. Biochem Biophys Res Commun. 2004;313(3): 702-708.

33. Greenberg A, Obin M. Obesity and the role of adipose tissue in inflammation and metabolism. Am J Clin Nutr. 2006;83(Suppl):461S-465S.

34. Moore K, Malefyt R, Coffman RL, O'Garra A. Interleukin-10 and the interleukin-10 receptor. Annu Rev Immunol. 2001;19(1):683-765.
35. Lira FS, Koyama CH, Yamashita AS, et al. Chronic exercise decreases cytokine production in healthy rat skeletal muscle. Cell Biochem Funct. 2009;27(7):458-461.

36. Daftarian PM, Kumar A, Kryworuchko A, Diaz-Mitoma F. IL-10 production is enhanced in human T cells by IL-12 and IL- 6 and in monocytes by tumor necrosis factor-alpha. J Immunol. 1996;157(1): 12-20.

37. Lira FS, Rosa JC, Yamashita AS, et al. Endurance training induces depotspecific changes in IL-10/TNF- $\alpha$ ratio in rat adipose tissue. Cytokine. 2009;45(2):80-85.

38. Kelley DE, Thaete FL, Troost F, et al. Subdivisions of subcutaneous abdominal adipose tissue and insulin resistance. Am J Physiol Endocrinol Metab. 2000;278(5):E941-E948.

39. Van Harmelen V, Lonnqvist F, Thorne A, et al. Noradrenaline-induced lipolysis in isolated mesenteric, omental and subcutaneous adipocytes from obese subjects. Int J Obes Relat Metab Disord. 1997;21(11): 972-979.

40. Hermsdorff HH, Monteiro JB. Visceral, subcutaneous or intramuscular fat: where is the problem? Arq Bras Endocrinol Metabol. 2004;48(6): 803-811.

41. Wajchenberg BL, Giannella-Neto D, Da Silva MER, Santos RF. Depot-specific hormonal characteristics of subcutaneous and visceral adipose tissue and their relation to the metabolic syndrome. Horm Metab Res. 2002;34(11-12):616-621.

42. Terry RB, Stefanick ML, Haskell WL, Wood PD. Contributions of regional adipose tissue depots to plasma lipoprotein concentrations in overweight men and women: possible protective effects of thigh fat. Metabolism. 1991;40:733.

43. Sjöström CD, Lissner L, Sjöström L. Relationships between changes in body composition and changes in cardiovascular risk factors: the SOS intervention study. Obes Res. 1997;5:519

44. Folsom AR, Kaye SA, Sellers TA. Body fat distribution and 5-year risk of death in older women. JAMA. 1993;269:1254.

45. Zhang C, Rexrode KM, Van Dam RM, et al. Abdominal obesity and the risk of all-cause cardiovascular, and cancer mortality. Sixteen year of follow-up in US women. Circulation. 2008;117:1658-1667.

46. Kral JG. Surgical reduction of adipose tissue hypercellularity in man. Scand J Plast Reconstr Surg. 1975;9:140.

47. ASAPS 2002 Statistics on Cosmetic Surgery. New York: American Society for Aesthetic Plastic Surgery; 2003.

48. Matarasso A, Hutchinson OH. Liposuction. JAMA. 2001;285(3): 266-268.

49. Guidelines for Liposuction Surgery. The American Academy of Cosmetic Surgery; 2006.

50. Perez RA. Liposuction and diabetes type 2 development risk reduction in the obese patient. Med Hypotheses. 2007;68(2):393-396.

51. Davis DA, Pellowski DM, Davis DA, Donahoo WT. Acute and 1-month effect of small-volume suction lipectomy on insulin sensitivity and cardiovascular risk. Int J Obes. 2006;30(8):1217-1222.

52. Matarasso A, Kim RW, Richard W, Kral JG. The impact of liposuction on body fat. Plast Reconstr Surg. 1998;102(5):1686-1689.

53. Giese SY, Bulan EJ, Commons GW, et al. Improvements in cardiovascular risk profile with large-volume liposuction: a pilot study. Plast Reconstr Surg. 2001;108:510-519.

54. Weber RV, Buckley MC, Fried SK, et al. Subcutaneous lipectomy causes a metabolic syndrome in hamsters. Am J Physiol Regul Integr Comp Physiol. 2000;279(3):936-943.

55. Busetto L, Bassetto F, Zocchi M, et al. The effects of the surgical removal of subcutaneous adipose tissue on energy expenditure and adipokine concentrations in obese women. Nutr Metab Cardiovasc Dis.2008;18:112-120.

56. Martínez-Abundis E, Molina-Villa CA, Gonzalez-Ortiz M, et al. Effect of surgically removing subcutaneous fat by abdominoplasty on leptin concentrations and insulin sensitivity. Ann Plast Surg. 2007;58(4):416-419.

57. Mohammed BS, Cohen S, Reeds D, et al. Long-term effects of largevolume liposuction on metabolic risk factors for coronary heart disease. Obesity. 2008;16(12):2648-2651.

58. Klein S, Fontana L, Young VL, et al. Absence of an effect of liposuction on insulin action and risk factors for coronary heart disease. $N$ Engl $J$ Med. 2004;350(25):2549-2557. 
59. Robles-Cervantes JA, Yanez-Diaz S, Cardenas-Camarena L. Modification of insulin, glucose and cholesterol levels in nonobese women undergoing liposuction: is liposuction metabolically safe? Ann Plast Surg. 2004;52(1):64-67.

60. Giugliano G, Nicoletti G, Grella E, et al. Effect of liposuction on insulin resistance and vascular inflammatory markers in obese women. $\mathrm{Br} J$ Plast Surg. 2004;57(3):190-194.

61. Gonzalez-Ortiz M, Robles-Cervantes JA, Cardenas-Camarena L, et al. The effects of surgically removing subcutaneous fat on the metabolic profile and insulin sensitivity in obese women after large-volume liposuction treatment. Horm Metab Res. 2002;34(8):446-449.

62. Ybarra J, Blanco-Vaca F, Castellvi FA, et al. The effects of liposuction removal of subcutaneous abdominal fat on lipid metabolism are independent of insulin sensitivity in normal-overweight individuals. Obes Surg. 2008;18(4):408-414.

63. Rizzo MP, Paoliosso G, Grella R, et al. Is dermolipectomy effective in improving insulin action and lowering inflammatory markers in obese women? Clin Endocrinol. 2005;63(3):253-258.

64. Gabriely I, Ma XH, Yang XM, et al. Removal of visceral fat prevents insulin resistance and glucose intolerance of aging: an adipokinemediated process? Diabetes. 2002;51(10):2951-2958.

65. Hong YG, Kim HT, Seo SW, et al. Impact of large-volume liposuction on serum-lipids in Orientals: a pilot study. Aesth Plast Surg. 2006;30: 327-332.

66. Kennedy GC. The role of depot fat in the hypothalamic control of food intake in the rat. Proc R Soc Lond B Biol Sci. 1953;140(901): 578-596.

67. Mauer MM, Harris RB, Bartness TJ. The regulation of total body fat: lessons learned from lipectomy studies. Neurosci Biobehav Rev. 2001; 25(1):15-28.

68. Bueno AA, Oyama LM, Estadella D, et al. Lipid metabolism of monosodium glutamate obese rats after partial removal of adipose tissue. Physiol Res. 2005;54(1):57-65.

69. Hausman DB, Lu J, Ryan DH, et al. Compensatory growth of adipose tissue after partial lipectomy: involvement of serum factors. Exp Biol Med. 2004;229(6):512-520.

70. Harris RB, Hausman DB, Bartness TJ. Compensation for partial lipectomy in mice with genetic alterations of leptin and its receptor subtypes. Am J Physiol Regul Integr Comp Physiol. 2002;283(5):1094-1103.

71. Coelho DF, Gualano B, Artioli GG, et al. Exercise training attenuates lipectomy-induced impaired glucose tolerance in rats. Endocr Regul. 2009;43(3):107-116.

72. Larson KA, Anderson DB. The effects of lipectomy on remaining adipose tissue depots in the Sprague Dawley rat. Growth. 1978;42: 469-477.

73. Rinomhota AS, Bulugahapitiya DUS, French SJ, et al. Women gain weight and fat mass despite lipectomy at abdominoplasty and breast reduction. Eur J Endocrinol. 2008;158:349-352.

74. Lambert EV, Hudson DA, Bloch CE, Koeslag JH. Metabolic response to localized surgical fat removal in nonobese women. Aesth Plast Surg 1991;15:105-110.

75. Chen MD, Ou LF, Song YM, et al. Postoperative plasma leptin levels in women undergoing suction lipectomy. Mayo Clin Proc. 2001;76(11): 1177-1178.

76. MacLean PS, Higgins JA, Johnson GC, et al. Enhanced metabolic efficiency contributes to weight regain after weight loss in obese-prone rats. Am J Physiol Regul Integr Comp Physiol. 2004;287(6): R1306-R1315.

77. Shi H, Strader AD, Woods SC, Seeley RJ. Sexually dimorphic responses to fat loss after caloric restriction or surgical lipectomy. Am J Physiol Endocrinol Metab. 2007;293:E316-E326.

78. Valle A, Catala-Niell A, Colom B, et al. Sex-related differences in energy balance in response to caloric restriction. Am J Physiol Endocrinol Metab. 2005;289:E15-E22.

79. Bailey JW, Anderson DB. Rate of fat compensation and growth efficiency of lipectomized Sprague Dawley rats. J Nutr. 1980;110:1785-1792.

80. Vermorel M, Lazzer S, Bittar A, et al. Contributing factors and variability of energy expenditure in non-obese, obese, and post-obese adolescents. Reprod Nutr Dev. 2005;45(2):129-142.
81. McMurray RG, Hackney AC. Interactions of metabolic hormones, adipose tissue and exercise. Sports Med. 2005;35(5):393-412.

82. Martin WH 3rd. Effects of acute and chronic exercise on fat metabolism. Exerc Sport Sci Rev. 1996;24:203-231.

83. Horowitz JF. Regulation of lipid mobilization and oxidation during exercise in obesity. Exerc Sport Sci Rev. 2001;29(1):42-46.

84. Boyd AE, Giamber SR, Mager M, Lebovitz HE. Lactate inhibition of lipolysis in exercising man. Metabolism. 1974;23:531-542.

85. Lange KHW. Fat metabolism in exercise - with special reference to training and growth hormone administration. Scand J Med Sci Sports. 2004;14:74-99.

86. Tunstall RJ, Mehan KA, Wadley GD, et al. Exercise training increases lipid metabolism gene expressio in human skeletal muscle. Am J Physiol Endocrinol Metab. 2001;283:66-72.

87. Houmard JA, Cox JH, MacLean PS, Barakat HA. Effect of shortterm exercise training on leptin and insulin action. Metabolism. 2000;49(7):858-861.

88. Zierath JR. Invited review: exercise training-induced changes in insulin signaling in skeletal muscle. J Appl Physiol. 2002;93:773-781.

89. Richter EA, Nielsen JN, Jorgensen SB, et al. Exercise signaling to glucose transport in skeletal muscle. Proc Nutr Soc. 2004;63: 211-216.

90. Hawley JA, Lessard SJ. Exercise training-induced improvements in insulin action. Acta Physiol. 2008;127-135.

91. Holloszy JO. Exercise-induced increase in muscle insulin sensitivity J Appl Physiol. 2005;99:338-343.

92. Hawley JA. Adaptations of skeletal muscle to prolonged, intense endurance training. Clin Exp Pharmacol Physiol. 2002;29:218-222.

93. Goodpaster BH, Katsiaras A, Kelley DE. Enhanced fat oxidation through physical activity is associated with improvements in insulin sensitivity in obesity. Diabetes. 2003;52:2191-2197.

94. Trayhurn P, Wood IS. Adipokines: inflammation and the pleiotropic role of white adipose tissue. Br J Nutr. 2004;92(3):347-355.

95. Reseland JE, Andersen SA, Solvoll K, et al. Effect of long-term changes in diet and exercise on plasma leptin concentrations. Am J Clin Nutr. 2001;73:240-245.

96. Kraemer RR, Kraemer GR, Acevedo EO, et al. Effects of aerobic exercise on serum leptin levels in obese women. Eur J Appl Physiol Occup Physiol. 1999;80(2):154-158.

97. Perusse L, Collier G, Gagnon J, et al. Acute and chronic effects of exercise on leptin levels in humans. J Appl Physiol. 1997;83(1):5-10.

98. Thong FS, Hudson R, Ross R, et al. Plasma leptin in moderately obese men: independent effects of weight loss and aerobic exercise. Am J Physiol Endocrinol Metab. 2000;279(2):E307-E313.

99. Hayase H, Nomura S, Abe T, Izawa T. Relation between fat distributions and several plasma adipocytokines after exercise training in premenopausal and postmenopausal women. J Physiol Anthropol Appl Human Sci. 2002;21(2):105-113.

100. Levin BE, Dunn-Meynell AA. Chronic exercise lowers the defended body weight gain and adiposity in diet-induced obese rats. Am J Physiol Regul Integr Comp Physiol. 2004;286:R771-R778.

101. Miyatake N, Takahashi K, Wada J, et al. Changes in serum leptin concentrations in overweight Japanese men after exercise. Diabetes Obes Metab. 2004;6(5):332-337.

102. Polak J, Klimcakova E, Moro C, et al. Effect of aerobic training on plasma levels and subcutaneous abdominal adipose tissue gene expression of adiponectin, leptin, interleukin 6, and tumor necrosis factor alpha in obese women. Metabolism. 2006;55(10):1375-1381.

103. Pasman WJ, Westerp-Plantenga MS, Saris WH. The effect of exercise training on leptin levels in obese males. Am J Physiol Endocrinol Metab. 1998;274:E280-E286.

104. Giannopoulou I, Fernhalla B, Carhart R, et al. Effects of diet and/or exercise on the adipocytokine and inflammatory cytokine levels of postmeno pausal women with type 2 diabetes. Metabolism. 2005;54: 866-868.

105. Hulver MW, Zheng D, Tanner CJ, et al. Adiponectin is not altered with exercise training despite enhanced insulin action. Am J Physiol Endocrinol Metab. 2002;283:E861-E865. 
106. Dvorakova-Lorenzova A, Suchanek P, Havel PJ, et al. The decrease in C-reactive protein concentration after diet and physical activity induced weight reduction is associated with changes in plasma lipids, but not interleukin-6 or adiponectin. Metabolism. 2006;55:359-365.

107. Rokling-Andersen MH, Reseland JE, Veierod MB. Effects of long-term exercise and diet intervention on plasma adipokine concentrations. Am J Clin Nutr. 2007;86:1293-1301.

108. Brekke HK, Lenner RA, Taskinen MR. Lifestyle modification improves risk factors in type 2 diabetes relatives. Diabetes Res Clin Pract. 2005;68:18-28.

109. Olson TP, Dengel DR, Leon AS, et al. Changes in inflammatory biomarkers following one year of moderate resistance training in overweight women. Int J Obes. 2007;31:996-1003.

110. Kriketos AD, Gan SK, Poynten AM, et al. Exercise increases adiponectin levels and insulin sensitivity in humans. Diabetes Care. 2004;27(2):629-630.

111. Esposito K, Pontillo A, Di Palo C, et al. Effect of weight loss and lifestyle changes on vascular inflammatory markers in obese women. JAMA. 2003;289:1799-1804.

112. Sheu WH, Chang T, Lee W, et al. Effect of weight loss on proinflammatory state of mononuclear cells in obese women. Obesity. 2008;16: 1033-1038.

113. Simpson KA, Singh MAF. Effects of exercise on adiponectin: a systematic review. Obesity. 2008;16:241-256.

114. Berggren JR, Hulver MW, Houmard JA. Fat as an endocrine organ: influence of exercise. J Appl Physiol. 2005;757-764.

115. Steinacker JM, Lormes W, Reissnecker S, Liu Y. New aspects of the hormone and cytokine response to training. Eur J Appl Physiol. 2004;91:382-391.

116. Akira S, Taga T, Kishimoto T. Interleukin-6 in biology and medicine. Adv Immunol. 1993;54:1-78.

117. Petersen AM, Pedersen BK. The anti-inflammatory effect of exercise. J Appl Physiol. 2005;98(4):1154-1162.

118. Starkie R, Ostrowski SR, Jauffred S, et al. Exercise and IL-6 infusion inhibit endotoxin-induced TNF-\{alpha\} production in humans. FASEB J. 2003;17(8):884-886.

119. Stewart LK, Flynn MG, Campbell WW, et al. The influence of exercise training on inflammatory cytokines and C-reactive protein. Med Sci Sports Exerc. 2007;39(10):1714-1719.

120. Ryan AS, Nicklas BJ. Reductions in plasma cytokine levels with weight loss improve insulin sensitivity in overweight and obese postmenopausal women. Diabetes Care. 2004;27:1699-1705.

121. Salas-Salvado J, Bullo M, Garcia-Lorda P, et al. Subcutaneous adipose tissue cytokine production is not responsible for the restoration of systemic inflammation markers during weight loss. Int J Obes. 2006; 30:1714-1720.

122. St-Onge M, Desmond R, Hunter G, et al. Baseline inflammatory markers do not modulate the lipid response to weight loss. Metabolism. 2008;57:598-604.

123. Tsukui S, Kanda T, Nara M, et al. Moderate intensity regular exercise decreases serum tumor necrosis factor-a and $\mathrm{HbAlc}$ levels in healthy women. Int J Obes Relat Metab Disord. 2000;24:1207-1211.

124. Straczkowski M, Kowalska I, Dzienis-Straczkowska S, et al. Changes in tumor necrosis factor-a system and insulin sensitivity during an exercise training program in obese women with normal and impaired glucose tolerance. Eur J Endocrinol. 2001;145:273-280.
125. Zahorska-Markiewicz B, Olszanecka-Glinianowicz M, Janowska J, Kocełak P. The effect of weight loss on serum concentrations of FAS and tumour necrosis factor alpha in obese women. Pol J Endocrinol. 2008;59(1):18-22.

126. You T, Berman DM, Ryan AS, Nicklas BJ. Effects of hypocaloric diet and exercise training on inflammation and adipocyte lipolysis in obese postmenopausal women. J Clin Endocrinol Metab. 2004;89: 1739-1746.

127. Ziccardi P, Nappo F, Giugliano G, et al. Reduction of inflammatory cytokine concentrations and improvement of endothelial functions in obese women after weight loss over one year. Circulation. 2002;105: 804-809.

128. Marfella R, Esposito K, Siniscalchi M, et al. Effect of weight loss on cardiac synchronization and proinflammatory cytokines in premenopausal obese women. Diabetes Care. 2004;27:47-52.

129. Chen HI, Hsieh SY, Yang FL, et al. Exercise training attenuates septic responses in conscious rats. Med Sci Sports Exerc. 2007;39(3): 435-442.

130. Sloan RP, Shapiro PA, Demeersman RE, et al. Aerobic exercise attenuates inducible TNF production in humans. J Appl Physiol. 2007;103(3): 1007-1011.

131. Forsythe LK, Wallace JMW, Livingstone MBE. Obesity and inflammation: the effects of weight loss. Nutr Res Rev. 2008;21:117-133.

132. Costa Rosa L. Exercise as a time-conditioning effector in chronic disease: a complementary treatment strategy. Evid Based Complement Alternat Med. 2004;1(1):63-70.

133. Wilmore JH, Després J-P, Stanforth PR. Alterations in body weight and composition consequent to $20 \mathrm{wk}$ of endurance training: the HERITAGE Family Study. Am J Clin Nutr. 1999;70:346-352.

134. Schmits KH, Hannan PJ, Stovitz SD, et al. Strength training and adiposity in premenopausal women: strong, healthy, and empowered study. Am J Clin Nutr. 2007;86:566-572.

135. Garrow JS, Summerbell CD. Meta-analysis: effect of exercise, with or without dieting, on the body composition of overweight subjects. Eur J Clin Nutr. 1995;49(1):1-10.

136. Van Angel-Leijssen D, Saris WHM, Wagenmakers AJM, et al. The effect of low-intensity exercise training on fat metabolism of obese women. Obes Res. 2001;9(2):86-96.

137. You T, Murphy KM, Lyles MF, et al. Adittion of aerobic exercise to dietary weight loss preferentially reduces abdominal adipocyte size. Int J Obes. 2006;30(8):1211-1216.

138. Ross R, Dagnone D, Jones PJ, et al. Reduction in obesity and related comorbid conditions after diet-induced weight loss or exercise-induced weight loss in men. Ann Intern Med. 2000;133:92-103.

139. Mourier A, Gautier J, DeKerviler E, et al. Mobilization of visceral adipose tissue related to the improvement in insulin sensitivity in response to physical training in NIDDM. Diabetes Care. 1997;20:385-391.

140. Kay SJ, Singh AF. The influence of physical activity on abdominal fat: a systematic review of the literature. Obes Rev. 2006;7:183-200.

141. Ohkawara K, Tanaka S, Miyachi M, et al. A dose-response relation between aerobic exercise and visceral fat reduction: systematic review of clinical trials. Int J Obes. 2007;31:1786-1797.

142. Habitante CA, Oyama LM, Bueno AA, et al. Exercise training in rats impairs the replenishment of white adipose tissue after partial lipectomy. Eur J Appl Physiol. 2010;109(3):371-377.

Diabetes, Metabolic Syndrome and Obesity: Targets and Therapy

\section{Publish your work in this journal}

Diabetes, Metabolic Syndrome and Obesity: Targets and Therapy is an international, peer-reviewed open-access journal committed to the rapid publication of the latest laboratory and clinical findings in the fields of diabetes, metabolic syndrome and obesity research. Original research, review, case reports, hypothesis formation, expert opinion and commentaries are all considered for publication. The manuscript management system is completely online and includes a very quick and fair peer-review system, which is all easy to use. Visit http://www.dovepress.com/testimonials.php to read real quotes from published authors. 